\title{
The role of dendritic cells in tumor microenvironments and their uses as therapeutic targets
}

\author{
Chae Won Kim ${ }^{1}$, Kyun-Do Kim ${ }^{2, *} \mathcal{E}$ Heung Kyu Lee ${ }^{1,3, *}$ \\ ${ }^{1}$ Graduate School of Medical Science and Engineering, Korea Advanced Institute of Science and Technology (KAIST), Daejeon 34141, \\ ${ }^{2}$ Center for Convergent Research of Emerging Virus Infection, Korea Research Institute of Chemical Technology, Daejeon 34114, \\ ${ }^{3}$ BioMedical Research Center, KAIST, Daejeon 34141, Korea
}

Dendritic cells (DC), which consist of several different subsets, specialize in antigen presentation and are critical for mediating the innate and adaptive immune responses. DC subsets can be classified into conventional, plasmacytoid, and monocyte-derived DC in the tumor microenvironment, and each subset plays a different role. Because of the role of intratumoral DCs in initiating antitumor immune responses with tumor-derived antigen presentation to T cells, DCs have been targeted in the treatment of cancer. By regulating the functionality of DCs, several DCbased immunotherapies have been developed, including administration of tumor-derived antigens and DC vaccines. In addition, DCs participate in the mechanisms of classical cancer therapies, such as radiation therapy and chemotherapy. Thus, regulating DCs is also important in improving current cancer therapies. Here, we will discuss the role of each DC subset in antitumor immune responses, and the current status of DC-related cancer therapies. [BMB Reports 2021; 54(1): 31-43]

\section{INTRODUCTION}

Cancers are a mass of abnormal cells proliferating out of control, and their progression often leads to death. Cancers can evade the immune system via an 'immunoediting' process that suppresses immunity and promotes tumor progression, causing the immune system to be exhausted (1). To reinvigorate exhausted immune cells, cancer immunotherapies have been developed that can block immune checkpoints, enable adoptive cell transfer, and be administered by means of vaccination. Within the cancer-immunity cycle, T cells are activated to ultimately kill cancer cells, and most strategies for cancer immunotherapy

*Corresponding authors. Kyun-Do Kim, Tel: +82-42-860-7493; Fax: +82-42-860-7160; E-mail: kdkim@krict.re.kr; Heung Kyu Lee, Tel: +8242-350-4241; Fax: +82-42-350-4240; E-mail: heungkyu.lee@kaist.ac.kr

https://doi.org/10.5483/BMBRep.2021.54.1.224

Received 19 October 2020, Revised 10 November 2020, Accepted 3 December 2020

Keywords: Cancer immunology, Cancer therapy, Dendritic cells have been focused on improving the functionality of T cells (2). Antigen-presenting cells (APCs) mediate T-cell activation in the cancer-immunity cycle and can capture, process, and present antigens from tumor cells to T cells. APCs consist of macrophages, dendritic cells (DCs), and B cells, which are characterized by the constitutive expression of major histocompatibility complex (MHC) class II and co-stimulatory molecules (3). Among these cells, DCs are the most capable APCs and are central to the initiation of antigen-specific immunity and tolerance. DC functions depend on environmental signals, such as cytokines, pathogen-associated molecular patterns, and damageassociated molecular patterns, which are sensed by extracellular and intracellular receptors, including pattern-recognition receptors (PRRs) (3). Therefore, controlling DC activity has considerable potential in improving antitumor immunity (4). Many therapies that manipulate the activation, migration, and function of DCs have undergone clinical trials (5). Furthermore, recent studies have reported the importance of DCs in cancer therapies, such as radiation therapy, chemotherapy, adoptive cell therapy, and immune-checkpoint blockade. In this article, we will discuss the role of DC subsets in tumor microenvironments and the potential use of these cells as therapeutic targets in patients with cancer.

\section{DCs IN CANCER IMMUNOLOGY}

DCs are typically divided into several subsets, including conventional DCs (cDCs), plasmacytoid DCs (pDCs), and monocytederived DCs (moDC), which are highly conserved between mouse and humans (summarized in Table 1). Each subset plays a different role in cancer immunology. Below we describe the function of each DC subset in cancer immunity (Fig. 1).

\section{CONVENTIONAL DCs (cDCs)}

cDCs are subdivided into two subtypes, known as type $1 \mathrm{cDC}$ (cDC1) and type 2 cDC (cDC2). These cDC subsets are distinguished by their expression of different transcription factors. CDC1 is primarily defined by the transcription factors BATF3 and IRF8. Type $1 \mathrm{cDCs}$ are also defined by cell-surface expression of $\mathrm{CD} 8 \alpha$ and $\mathrm{CD} 103$, with $\mathrm{CD} 8 \alpha^{+} \mathrm{CDC} 1$ s considered to

ISSN: 1976-670X (electronic edition)

Copyright (C) 2021 by the The Korean Society for Biochemistry and Molecular Biology

(c) This is an open-access article distributed under the terms of the Creative Commons Attribution Non-Commercial License (http://creativecommons.org/licenses/by-nc/4.0) which permits unrestricted non-commercial use, distribution, and reproduction in any medium, provided the original work is properly cited. 
Table 1. DC subsets in mouse and human

\begin{tabular}{llll}
\hline \multirow{2}{*}{ DC subset } & \multicolumn{2}{c}{ Transcription factors } & \multicolumn{1}{c}{ Main surface markers } \\
\cline { 3 - 4 } & & \multicolumn{1}{c}{ Mouse } & Human \\
\hline pDC & IRF7 & CD45R, CD45RA, CD317 & CD123, CD303, CD304, CD45RA \\
CDC1 & BATF3, IRF8, BCL-6, ID2, ZBTB46 & CD8 $\alpha$ or CD103, DEC205, Clec9A, XCR1 & CD141, DEC205, Clec9A, XCR1 \\
CDC2 & IRF4, ID2, NOTCH2, ZBTB46 & CD11b, Sirp $\alpha$ & CD1c, CD11b, CD1a (migratory) \\
moDC & MAFB, KLF4, ZBTB46 & Ly6C, CD64, CCR2, CD14 & CD1c, CD1a, CD14, CD64, CD206 \\
\hline
\end{tabular}

pDC, plasmacytoid DC; CDC1, conventional DC 1; CDC2, conventional DC 2; moDC, monocyte-derived DC; BATF3, basic leucine zipper transcription factor ATF-like 3; BCL-6, B cell lymphoma 6 protein; CCR, CC-chemokine receptor; ID2, inhibitor of DNA binding 2; IRF, interferon-regulatory factor; KLF4, Kruppel-like factor 4; Ly6C, lymphocyte antigen 6 complex; MAFB, MAF BZIP transcription factor B; NOTCH2, neurogenic locus notch homolog protein 2; XCR1, chemokine XC receptor 1; ZBTB46, zinc-finger and BTB domain-containing 46.

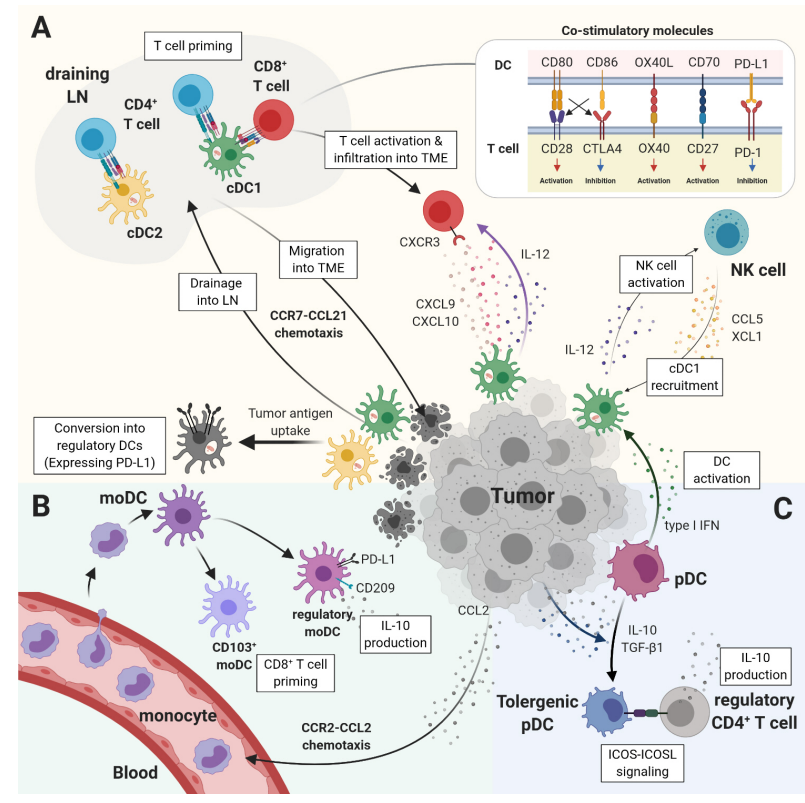

Fig. 1. Immune regulation of DC subsets in tumor microenvironment (TME). (A) cDCs uptake tumor-derived antigens and migrate into draining $\mathrm{LNs}$ in order to present antigens to $\mathrm{T}$ cells. CDC1s are required for both $\mathrm{CD}^{+}$and $\mathrm{CD}^{+}$T-cell priming, but $\mathrm{CDC} 2 \mathrm{~s}$ are needed only for $\mathrm{CD}^{+} \mathrm{T}$ cells. The migration of cDCs between LNs and TME is driven by CCR7-CCL21 chemotaxis. The recruitment of activated T cells into TME is dependent on CXCL9 and CXCL10, ligands of CXCR3, produced by cDC1s. The co-stimulatory molecules expressed by DCs positively or negatively regulate T-cell activation. NK cells induce the recruitment of $\mathrm{CDC} 1 \mathrm{~s}$ via CCL5 and XCL1 chemokine secretions, and CDC1s increase NK- cell activation via IL-12 production. Upon tumor antigen uptake, cDCs are genetically programmed to convert into regulatory DCs expressing PD-L1. (B) CCL2 expressed in TME recruit blood-circulating monocytes, which can differentiate into moDCs. Whereas moDCs can become $\mathrm{CD}_{103}{ }^{+} \mathrm{DCs}$ activating $\mathrm{CD}^{+} \mathrm{T}$ cells, they can also be regulatory DCs, with the expression of PD-L1 and CD209, producing IL-10. (C) pDCs produce considerable type I IFNs activating cDCs. However, immunosuppressive cytokines (IL-10 and TGF- $\beta 1$ ) produced by tumor cells induce the conversion of pDCs into ICOS-L-expressing tolerogenic pDCs, which promote ICOS-positive regulatory $\mathrm{CD}^{+} \mathrm{T}$ cells to produce IL-10. be lymphoid organ-resident $\mathrm{CDC} 1 \mathrm{~s}$, and $\mathrm{CD}_{103}{ }^{+} \mathrm{CDC} 1 \mathrm{~s}$ considered to be tissue-resident or migratory CDC1s (5). CDC2 is frequently defined by the transcription factor IRF4 and surface expression of CD11b, CD1c, and SIRP $\alpha$ (5).

In the antitumor immune responses, $\mathrm{CDC} 1 \mathrm{~s}$ are critical in tumor rejection and responses to immunotherapies, such as immune-checkpoint blockade and adoptive T-cell therapy (6-8). $\mathrm{CD}^{+} \mathrm{T}$ cells are important effector cells involved in eliminating tumor cells, and cDC1s play an important role by cross-presenting tumor-associated antigens to $\mathrm{CD}^{+} \mathrm{T}$ cells (Fig. 1A). BATF3 deficiency in mice results in $\mathrm{CD} 8 \alpha^{+}$DCs that cannot cross-present to $\mathrm{CD}^{+}{ }^{+} \mathrm{T}$ cells, leading to lack of tumor rejection (6). In humans, activation of CD $141^{+}$DCs with Toll-like receptor 3 (TLR3) agonist leads to cross-presentation of antigens from necrotic cells to $\mathrm{CD}^{+} \mathrm{T}$ cells (9). In addition to CDC1s, $\mathrm{CD}^{+} \mathrm{T}$ helper cells are important in inducing the cytotoxic function of $\mathrm{CD}^{+}{ }^{\mathrm{T}}$ cells, and $\mathrm{CD} 4^{+} \mathrm{T}$-cell priming is typically considered to be in charge of $\mathrm{CDC} 2 \mathrm{~s}$. Research from the Krummel group suggests that $\mathrm{CDC} 2 \mathrm{~s}$ do not participate in the activation of $\mathrm{CD}^{+}{ }^{+} \mathrm{T}$ cells in antitumor immune responses $(10,11)$. They found two DC populations, $\mathrm{CD} 11 \mathrm{~b}^{+}$and $\mathrm{CD}_{103}{ }^{+}$subsets, among tumor-infiltrating myeloid immune cells, and found that $\mathrm{CD} 11 \mathrm{~b}^{+}$DCs rarely stimulate naïve and activated $\mathrm{CD} 8^{+} \mathrm{T}$ cells (10). Furthermore, CD11 $b^{+}$DCs in tumor-draining LNs cannot induce the proliferation of naïve $\mathrm{CD}^{+} \mathrm{T}$ cells (11). However, cDC2s are involved in antitumor immune responses by inducing the proliferation of antitumor $\mathrm{CD} 4^{+} \mathrm{T}$ cells (12). A recent study showed that both $\mathrm{CD} 4^{+}$and $\mathrm{CD}^{+}{ }^{+} \mathrm{T}$ cells are required for tumor rejection and selective deletion of $\mathrm{MHC}$ class II in cDC1s, as well as inhibition of early $\mathrm{CD}^{+}{ }^{+} \mathrm{T}$-cell priming, suggesting that $\mathrm{cDC} 1 \mathrm{~s}$ and $\mathrm{cDC} 2 \mathrm{~s}$ are required for CD4 ${ }^{+}$T-cell priming (13).

cDC1s can capture and deliver tumor-associated antigens to lymphocytes in draining $\mathrm{LNs}(\mathrm{dLNs})$, leading to the activation of tumor antigen-specific $\mathrm{CD}^{+} \mathrm{T}$ cells (Fig. 1A). Migratory $\mathrm{CD}_{103}{ }^{+}$DCs can carry tumor antigen and accumulate in tumordraining LNs. CC chemokine receptor-7 (CCR7) deficiency abrogates the accumulation of $\mathrm{CD}_{103}{ }^{+} \mathrm{DCs}$ in $\mathrm{LNs}$, thereby inhibiting $\mathrm{CD}^{+}$T-cell priming $(11,14)$. In addition, the expression 
level of CCR7 in human tumors has been correlated with signatures of $\mathrm{CD} 141^{+}$DCs, tumor-infiltrating T cells, and improved clinical prognosis (11). CC chemokine ligand-21 (CCL21) expressed by tumor cells induces trafficking of CCR7 ${ }^{+}$DCs into the tumor microenvironment $(15,16)$. Injection of engineered melanoma cells that express CCL21 significantly inhibited tumor growth more than normal melanoma cells did and increased CD11 ${ }^{+}$DCs and T cells in the tumor microenvironment (15). In contrast, another study showed that CCL21 expression in melanoma cells was associated with an immunotolerogenic microenvironment characterized by decreased interferon- $\gamma$ (IFN- $\gamma$ ), increased tumor growth factor beta-1 (TGF- $\beta 1$ ), and recruitment of regulatory T cells (16).

In addition to antigen presentation, $\mathrm{cDCs}$ have other ways to induce antitumor immune responses, in particular, the priming and activation of $\mathrm{CD}^{+} \mathrm{T}$ cells, via co-stimulatory molecules and soluble factors (Fig. 1A). Several co-stimulatory molecules are expressed on cDCs, such as CD80, CD86, OX40 ligand (OX40L), and CD70. CD80 and CD86 increase T-cell activation and suppression by interacting with CD28 or cytotoxic T lymphocyte antigen 4 (CTLA4), respectively (17). Moreover, interactions with other co-stimulatory molecules expressed on DCs support T-cell-mediated immune responses. Related studies have focused primarily on cancer immunotherapy. DCs transfected with mRNA encoding ox 40 l induce Th1 responses and $\mathrm{CD}^{+} \mathrm{T}$-cell priming, leading to an increase in antitumor immunity (18). In addition, expression of CD70, a ligand for CD27, on DCs is essential for $\mathrm{CD}^{+}{ }^{+}$T-cell priming and antitumor immunity in mice, and administration of an agonist anti-CD27 monoclonal antibody (mAb) synergizes with programmed cell death protein-1 (PD-1) blockade (19).

Soluble factors, such as cytokines and chemokines secreted by CDCs, are essential for the activation and trafficking of $\mathrm{T}$ cells in the tumor microenvironments (Fig. 1A). One important cytokine involved in inducing antitumor immunity is interleukin-12 (IL-12). cDC1s are considered to be the main producer of IL-12 in cancer immunology $(10,20,21)$. BATF3-dependent $\mathrm{CD} 103^{+}$DCs largely produce IL-12 for the generation of T-cell-mediated immune responses (20). Among tumor-infiltrating myeloid cell populations, $\mathrm{CD} 103^{+} \mathrm{DC}$ subsets predominantly express IL-12 (10). IL-12 expression on DCs is suppressed by signaling of IL-10 produced by macrophages, which results in reduced tumor rejection and response to chemotherapy (21). cDCs are also involved in trafficking of T cells to the tumor microenvironment via chemokine production $(8,22,23)$. Tumor-infiltrating $\mathrm{T}$ cells expressing CXC motif chemokine receptor-3 (CXCR3) and its ligands CXCL9 and CXCL10 are mainly expressed by $\mathrm{CD}_{103}{ }^{+} \mathrm{DC}$ subsets. Selective depletion of BATF3 in $\mathrm{CD}_{11 \mathrm{c}^{+}}$cells cannot recruit effector T cells into the tumor microenvironment (8). Transferred central memory $\mathrm{CD}^{+} \mathrm{T}$ cells specific to tumor-derived antigens can generate resident memory $T$ cells following tumor challenge, and BATF3depdendent DC subsets are essential for the reactivation of circulating memory antitumor responses (23). Additionally, where- as CXCR3 deficiency did not critically affect $\mathrm{CD}^{+}$T-cell recruitment, CXCL3 and CXCL9 production by $\mathrm{CD} 103^{+} \mathrm{DCs}$ is required for the response to PD-1 blockade (22). In summary, the $\mathrm{CDC} 1$ subset is critical in mediating $\mathrm{CD} 8{ }^{+} \mathrm{T}$-cell activation and antitumor immune responses via cross-presentation, co-stimulation, and soluble factors, whereas the cDC2 subset is involved in antitumor immunity via $\mathrm{CD} 4^{+} \mathrm{T}$-cell activation.

Recent studies identified an interplay between natural killer (NK) cells and cDC1s (Fig. 1A). In a murine melanoma model, IL-12 produced by $\mathrm{CD} 103^{+}$DCs activated NK cells to secrete IFN- $\gamma$, which is critical for suppressing tumor-cell metastasis independent of $\mathrm{CD}^{+}$and $\mathrm{CD} 8^{+} \mathrm{T}$ cells (24). Conversely, NK cells can recruit $\mathrm{CDC} 1 \mathrm{~s}$ into the tumor microenvironment via the chemokines CCL5 and XCL1, and this NK-DC axis is associated with cancer-patient survival (25). In human melanoma, cDC1 abundance is associated with intratumoral tissue expression of FLT3LG, a cytokine produced mainly by NK cells in the tumor microenvironment (26). Cross-talk between CDC1s and NK cells, as well as interplay between cDCs and other immune cells, in the tumor microenvironment is complex and important for understanding the overall regulation of antitumor immune responses.

Although $\mathrm{cDC} 1 \mathrm{~s}$ reduce tumor growth, this subset can still be found in tumors that resist immune-checkpoint blockade. A recent study using single-cell RNA sequencing identified a mature DC subset that expresses immuno-regulatory genes, including $\mathrm{cd} 274$, pdcd1/g2, cd200, and maturation genes, including $c c r 7$ and $i / 12 b$ (27). Both cDC1 and cDC2 cells are programmed to differentiate into this regulatory subset upon uptake of tumor antigens. In addition, the expression of programmed cell death ligand 1 protein (PD-L1) in this subset is induced by receptor tyrosine kinase $\mathrm{AXL}$, and IL-12 is negatively regulated by IL-4 signaling (27). Thus, cDCs play an immunoregulatory role in the tumor microenvironment (Fig. 1A).

In addition, tumors can regulate DCs to suppress antitumor activities. Tumor cells produce several molecules, such as IL-6, gangliosides, prostanoids, and lactic acid, that can regulate DC differentiation $(28,29)$. DCs can sense tumor-derived mitochondrial DNA via signal regulatory protein alpha (SIRP $\alpha$ ); however, CD47 expressed by tumor cells can inhibit SIRPa resulting in decreased expression of type I IFNs (30). Liver X receptor alpha $(\mathrm{LXR} \alpha)$ derived from tumor cells can restrict the migration of DCs via CCR7 into the tumor microenvironment (31). While DCs have antitumor functions, it is possible for tumor cells to restrict DCs' abilities to protect themselves from attack.

\section{PLASMACYTOID DCs (pDCs)}

Whereas $\mathrm{cDCs}$ and pDCs are derived from common DC progenitors, these subsets possess considerably different characteristics and functions (5). As mentioned above, antigen presentation is the main role of cDCs. Although pDCs express MHCII and co-stimulatory molecules, their main function is to pro- 
duce type I IFNs and pro-inflammatory cytokines in response to TLR signaling that is activated by viral RNA and DNA during infection (32). Whereas type I IFNs are known for their important role in antiviral immune responses, they are also involved in antitumor immune responses by regulating type I IFN receptor-expressing immune cells, including DCs (Fig. 1C) (33). In human metastatic melanoma, the transcriptional profile of type I IFNs correlates with T-cell markers, and IFNAR1 (IFN- $\alpha / \beta$ receptor 1 )-deficient mice cannot induce T-cell priming in the tumor microenvironment (34). Furthermore, IFNAR1-deficient DCs cannot reject highly immunogenic tumor cells because of defects in their cross-presenting function to $\mathrm{CD}^{+}$ DCs (35).

The role of pDCs has not been well established in cancer immunology. In lung cancer, the expression of pDC genes in tumor tissues is associated with a positive prognosis (36). Whereas pDCs are associated with good prognosis in lung cancer, most studies have reported a negative prognosis in several tumor types and a tolerogenic role for pDCs in antitumor immunity (Fig. 1C) (37-43). The infiltration of pDCs in ovarian cancer is associated with early relapse and a poor survival rate (40). pDCs accounted for the largest percentage in inducible co-stimulatory ligand (ICOS-L)-positive immune cells in human ovarian-cancer tissues, and they stimulated $\mathrm{ICOS}^{+}$ $\mathrm{FOXP}^{+}{ }^{+}$regulatory $\mathrm{T}$ cells to suppress antitumor immune responses (38). Besides ovarian cancer, the presence of pDCs in the tumor microenvironment of breast cancer is associated with a negative prognosis (42). ICOS-L ${ }^{+}$pDCs promote breast-cancer growth via the accumulation of regulatory $\mathrm{CD}^{+} \mathrm{T}$ cells following ICOS stimulation (39). Furthermore, pDCs from the melanoma environment induce naïve $\mathrm{CD} 4^{+} \mathrm{T}$ cells to express Th2 immunity-related cytokines (e.g., IL-5) and anti-inflammatory cytokines (e.g., IL-10), which are regulated by OX40-L and ICOS-L expression on pDCs, respectively (37). Similarly, in human liver tumors, pDCs are enriched at the tumor site, and their presence has been correlated with increased frequency of regulatory $\mathrm{CD} 4^{+} \mathrm{T}$ cells, which produce IL-10 via ICOS-ICOS-L signaling (41). In addition to $\mathrm{CD}^{+}{ }^{+}$cells, pDCs in the ovarian carcinoma microenvironment induce regulatory $\mathrm{CD}^{+} \mathrm{T}$ cells to produce IL-10, suppressing the effector functions of tumor antigen-specific T cells (43).

The tumor microenvironment regulates the immunotolerogenic functions of pDCs via several mechanisms (Fig. 1C). TGF- $\beta 1$ and tumor necrosis factor-alpha (TNF- $\alpha$ ) secreted by breast tumor cells suppress the production of type I IFN by pDCs and the expression of IRF7 on pDCs (44). pDCs with an activated profile accumulate in murine lung tumor and melanoma models, and TGF- $\beta 1$ present in tumor-cell supernatant can inhibit IFN- $\alpha$ production by pDCs after stimulation with the TLR9 agonist CpG (45). In addition, IL-10 produced by head and neck cancer cells suppresses IFN- $\alpha$ production, and this suppression is reversible with the addition of an IL-10 receptor antagonistic antibody (46). Whereas pDCs activated by $\mathrm{CpG}$ can inhibit growth and induce apoptosis in myeloma cells by secreting
IFN- $\alpha$, pDCs are converted into tumor-promoting cells by direct interaction with E-cadherin on myeloma cells, resulting in TLR9 ubiquitination and degradation, as well as inhibition of IFN- $\alpha$ production by pDCs (47). In summary, in most tumor types, pDCs play a tolerogenic role by regulating tumor cells, which leads to the accumulation of regulatory $\mathrm{T}$ cells in the tumor microenvironment.

\section{MONOCYTE-DERIVED DCs (moDCs)}

During inflammatory responses, $\mathrm{Ly}^{6} \mathrm{C}^{+}$(mouse) or $\mathrm{CD} 14^{+}$(human) monocytes migrate into the inflammatory site and differentiate into DCs called monocyte-derived DCs (moDCs) (Fig. 1B) (4, 5). Monocytes in the blood directly migrate into dLNs and differentiate into $\mathrm{CD} 11 \mathrm{c}^{+} \mathrm{CD} 11 \mathrm{~b} \mathrm{bi}^{\mathrm{hi}} \mathrm{Gr}-1^{+}$moDCs after initiation of the inflammatory response to produce IL-12 and stimulate Th1 responses (48). In the tumor microenvironment, a portion of $\mathrm{CD}_{103}{ }^{+} \mathrm{DCs}$, which are known for cross-presentation, express Ly6C derived from monocytes. This differentiation is dependent on p53 activation and leads to BATF3 upregulation and acquisition of their moDC phenotype. This mechanism is supported by reports demonstrating that selective deletion of p53 in myeloid cells results in selective loss of $\mathrm{Ly}_{6 \mathrm{C}} \mathrm{CD}^{+} \mathrm{CD} 3^{+}$ moDCs and decreased response to immunotherapy (49). In addition, moDCs in the melanoma microenvironment can increase the proliferation of $\mathrm{CD}^{+} \mathrm{T}$ cells and cross-present antigens as effectively as CDC subsets (50). Monocytes are recruited into the tumor microenvironment by CCL2 derived from tumor cells, which play a chemotactic role (51).

Whereas moDCs may possess an antitumor phenotype, they can differentiate into immunosuppressive cells (Fig. 1B). Stromal factors, including CCL2, IL-6, and TGF- $\beta 1$, produced by tumorassociated stromal myofibroblasts induce monocytes to express CD209 and PD-L1. Upon lipopolysaccharide (LPS) stimulation, these moDCs produce considerably more IL-10 and less IL-12 than do CDC subsets, fail to cross-present tumor antigen to $\mathrm{CD}^{+}{ }^{+}$cells, and suppress T-cell proliferation (52). In addition, although moDCs can skillfully take up tumor antigens, they are defective in providing sufficient stimulation to activate $T$ cells because of nitric-oxide-mediated immunosuppression (53).

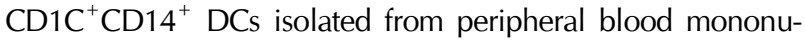
clear cells (PBMCs) of melanoma patients exhibit features like those of monocytes; however, they can produce more IL-10 than monocytes can following TLR agonist stimulation. This subset can induce T-cell responses, but these responses are decreased by their PD-L1 expression (54). Thus, moDCs are induced with the occurrence of tumors, and whether they ultimately possess an antitumor or protumor phenotype is determined by the tumor microenvironment.

\section{DCs AND CANCER THERAPIES}

Thus far, various therapies, including radiation therapy, chemotherapy, adoptive T-cell, and immune-checkpoint blockade, are 
used to treat cancer patients. DCs are critical in cancer therapy and play a role in determining therapeutic efficacy. Here, we discuss how DCs are involved in the mechanism of various cancer therapies (Fig. 2).

\section{RADIATION THERAPY AND CHEMOTHERAPY}

Radiation therapy involves treating patients with external beams, such as X-rays, whereas chemotherapy involves administering pharmaceutical agents such as oxaliplatin, doxorubicin, or anthracycline. Both types of therapies aim to damage DNA or inhibit cell division, resulting in tumor-cell death. Although these therapies directly eliminate tumor cells, they can also induce antitumor immune responses in DCs via immunogenic cell death (Fig. 2A).

As tumor cells are eliminated, several molecules, such as tumor-derived DNA, ATP, and high mobility group box 1 (HMGB1), are released in the tumor microenvironment to activate $\mathrm{DCs}$, resulting in an antitumor immune response. Tumorderived DNA can bind to cyclic GMP-AMP Synthase (cGAS) and activate signaling by stimulating cytosolic stimulator of interferon genes (STING) in DCs, leading to the induction of type I IFNs, which are key mediators in the efficacy of radiation therapy (55). ATP is another activator of DCs in the mechanism to induce T-cell priming. When oxaliplatin attacks tumor cells, ATP is released from dying tumor cells and acts on purinergic $\mathrm{P}_{2} \mathrm{X}_{7}$ receptors of DCs to activate the NOD-like receptor family, pyrin domain containing-3 protein (NLRP3) inflammasome, leading to IL-1 $\beta$ secretion (56). In addition, HMGB1 is selectively released by dying tumor cells after chemotherapy or radiation therapy and activates TLR4 signaling in DCs, which regulates the processing and presentation of tumor-cell antigens by DCs (57). Furthermore, dying tumor cells express annexin-1, which interacts with formyl peptide receptor 1 (FPR1) expressed by DCs, leading to T-cell activation (58).

However, these therapies do not always induce antitumor immune responses via immunogenic cell deaths. A recent study showed the opposite results in acute human leukemia cells, namely, that DCs cultured with doxorubicin-treated tumor cells upregulated indoleamine 2,3-dioxygenase 1 (IDO1), thereby inducing regulatory $T$ cells because of elevated levels of extracellular ATP (59). During high-dose radiation therapy, DNA exonuclease Trex1 is induced and degrades cytosolic DNA, resulting in attenuated cGAS-STING signaling (60). In addition,
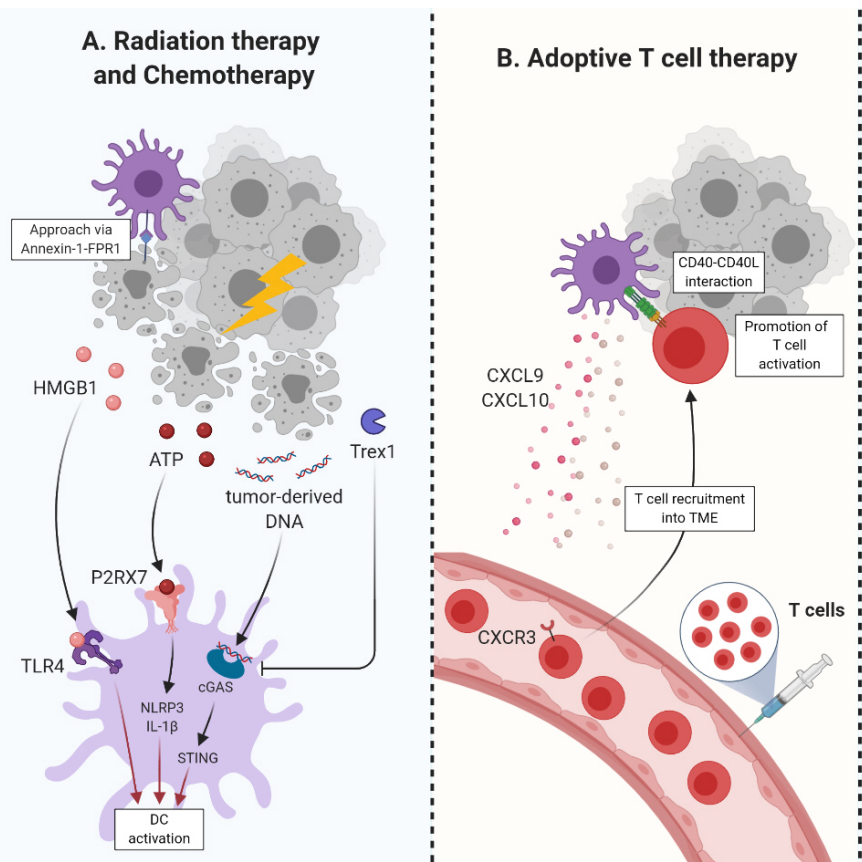

C. Immune checkpoint blockade (ICB)

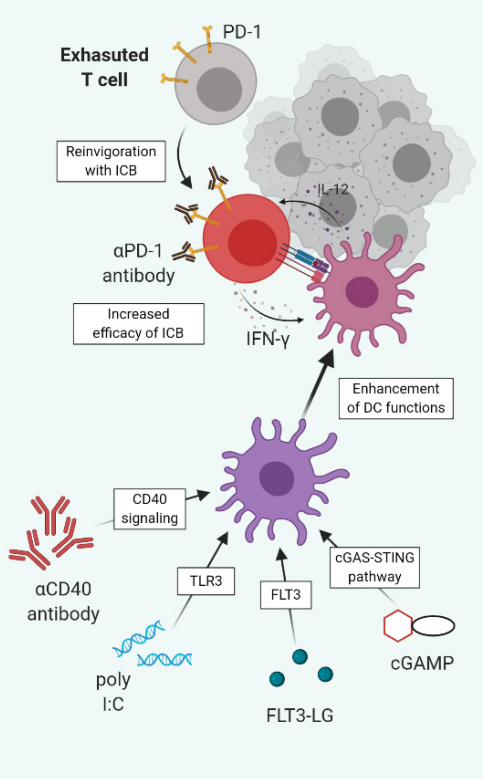

Fig. 2. The role of DCs in cancer therapies. (A) Tumor-cell deaths, induced by radiation therapy and chemotherapy, release various molecules activating or inhibiting immune responses of DCs in TME. As binding to TLR4, HMGB1 can elicit the activation of DCs. ATP binds to P2X7 receptor, triggering NLRP3 inflammasome and promoting IL-1 $\beta$ secretion. Tumor-derived DNA also induces a cGAS-STING pathway leading to DC activation. However, Trex1 suppresses the CGAS-STING pathway by degrading tumor-derived DNA. (B) DCs can increase the efficacy of adoptive T-cell therapy. CXCL9 and CXCL10 chemokines produced by DCs promote T-cell recruitment into tumor sites. CD40-CD40L interactions between DCs and T cells intensify the activation of T cells. (C) In terms of ICB therapy, IL-12 produced by DCs is required for PD-1 blockade. At the same time, DCs must sense IFN-r produced by T cells. Because improved DC functions can elevate the efficacy of ICB therapy, DC-activating adjuvants are combined with ICB, such as aCD40 antibody, poly I:C, FLT3-LG, and cGAMP. 
radiation therapy stimulates CGAS-STING signaling, which activates the canonical and non-canonical NF-kB pathways in DCs. The non-canonical pathway can suppress the canonical one, which is critical for inducing type I IFNs (61).

\section{ADOPTIVE T-CELL THERAPY}

Adoptive T-cell therapy involves harvesting T cells from patients' tumoral tissues or peripheral blood, expanding them, and then reinfusing the cells into the patient in order to attack tumor cells. As mentioned above, DCs are critical for T-cell priming in antitumor immunity. Likewise, DCs are required for effective adoptive T-cell therapy (Fig. 2B). For adoptive CD8 ${ }^{+}$ T-cell therapy, it is important for TNF and inducible nitric-oxidesynthase (iNOS)-producing DCs (Tip-DCs) to produce nitric oxide to induce tumor killing, and Tip-DCs require the CD40-CD40L interactions with infused $\mathrm{CD}^{+} \mathrm{T}$ cells (62). In addition to Tip-DCs, CD40 and CD70 signaling, but not CD80/CD86, in the $\mathrm{CDC} 1$ subset are critical for expanding adoptively transferred T cells (63). Furthermore, lack of $\mathrm{CD} 103^{+}$DCs limits the efficacy of adoptive T-cell therapy, because CXCL9 and CXCL10 produced by $\mathrm{CD}_{103}{ }^{+}$DCs in the tumor microenvironment are essential for infused T cells, as well as endogenous effector $\mathrm{T}$ cells, to traffic to the tumor sites and increase antitumor immunity (8).

\section{IMMUNE-CHECKPOINT BLOCKADE}

Immune-checkpoint blockade (ICB) is a strategy aimed at inhibiting interactions with immune checkpoints that can suppress antitumor immune responses. For example, PD-L1 on tumor cells can suppress the antitumor functions of T cells by PD-1/ PD-L1 interaction. PD-1/PD-L1 blockade can reinvigorate T-cell functions leading to tumor rejection, and this treatment is currently in clinical use for cancer patients. However, ICB treatment is limited by the responsiveness rate, because its effectiveness depends on the type of cancer and the state of immune cells in the cancer patient (64). Therefore, it is important to understand the immunological situation of the tumor microenvironment in order to elevate the response rate to ICB.

The infiltration of DC subsets into the tumor microenvironment is associated with the response to anti-PD-1 or anti-PD-L1 immunotherapy. In human melanoma patients, the proportion of $\mathrm{CDC} 1$ subsets in intratumoral tissues is significantly higher in PD-1 blockade-responsive patients than in non-responsive patients (26). Studies investigating the RNA-seq data of tumor tissues from renal-cell carcinoma (RCC) and non-small-cell lungcarcinoma patients found that the gene signature of DCs is associated with an improved survival rate following anti-PD-L1 immunotherapy (atezolizumab) (65). These associations suggest that DCs are key players in response to ICB therapy (Fig. 2C). Indeed, BATF3-deficient mice with melanoma injection cannot respond to anti-PD-L1 immunotherapy. Administering a combination of poly I:C and FMS-like tyrosine kinase 3 ligand (FLT3LG), which stimulates DC differentiation and expansion, produces a synergistic effect with anti-PD-L1 immunotherapy, leading to better antitumor responses (14). Likewise, BATF3 deficiency also inactivates the responses to combined anti-PD-1 and anti-CD137 immunotherapy and the synergistic effect of poly I:C and FLT3LG (7). In addition to CDC1s, a recent study showed that moDCs, especially iNOS-producing Tip-DCs, are important in the response to PD-1 blockade (66).

Even though the presence of DCs is important for responsiveness to ICB, the functionality of DCs may improve the efficacy of this therapy. Anti-CD40 agonist antibody can promote DC differentiation and proliferation in the tumor microenvironment, resulting in systemic T-cell activation that produces a synergistic effect with ICB (66-68). In addition, engineered type I IFN targeting to DCs improves the functionality of DCs in antitumor immune responses and the efficacy of PD-L1 blockade (69). IL-12 produced by DCs is also required to reinvigorate exhausted CD8 ${ }^{+}$T-cells for successful PD-1 blockade, and these DCs also have to sense $\mathrm{CD}^{+}{ }^{+} \mathrm{T}$-cell-producing IFN- $\gamma$ (68). Additionally, cGAS- or STING-deficient mice cannot respond to PD-L1 blockade and generate tumor-infiltrating $\mathrm{CD}^{+} \mathrm{T}$ cells. Also, administration of the STING ligand cyclic guanosine monophosphate-adenosine monophosphate (cGAMP) may increase the efficacy of anti-PD-L1 immunotherapy (70). Furthermore, cross-presentation of DCs, which is dependent on Sec22b, is required for the responsiveness to PD-1 blockade (71). Therefore, considering the regulation of DCs is important in increasing responsiveness to ICB.

\section{DC-BASED IMMUNOTHERAPIES}

DCs are an important mediator between the innate and adaptive immune responses against tumors. Thus, one effective treatment strategy is to target DCs, focusing on their functional improvement, expansion, and tumor-derived antigen specificities (Fig. 3).

\section{ACTIVATION OF DCs}

One method to increase the functionality of DCs is to administer cytokines, such as FLT3LG and granulocyte-macrophage colony-stimulating factor (GM-CSF), which promote the differentiation and activation of DCs (Fig. 3A). FLT3LG administration has been reported to suppress tumor growth in a murine tumor model, and in vitro stimulation with FLT3LG promotes the upregulation of co-stimulatory molecules and MHCll expression on bone-marrow-derived DCs (BM-DCs). Moreover, in vivo FLT3LG injection considerably augments $\mathrm{CD} 103^{+} \mathrm{DC}$ progenitors in the bone marrow and promotes their accumulation and expansion in the tumor microenvironment (14). GM-CSF is another important factor involved in the differentiation, activation, and migration of DCs, and numerous studies focused on GM-CSF-based immunotherapy have been published. One representative strategy using GM-CSF is GVAX, a cancer-cell 
B. Delivery of antigens

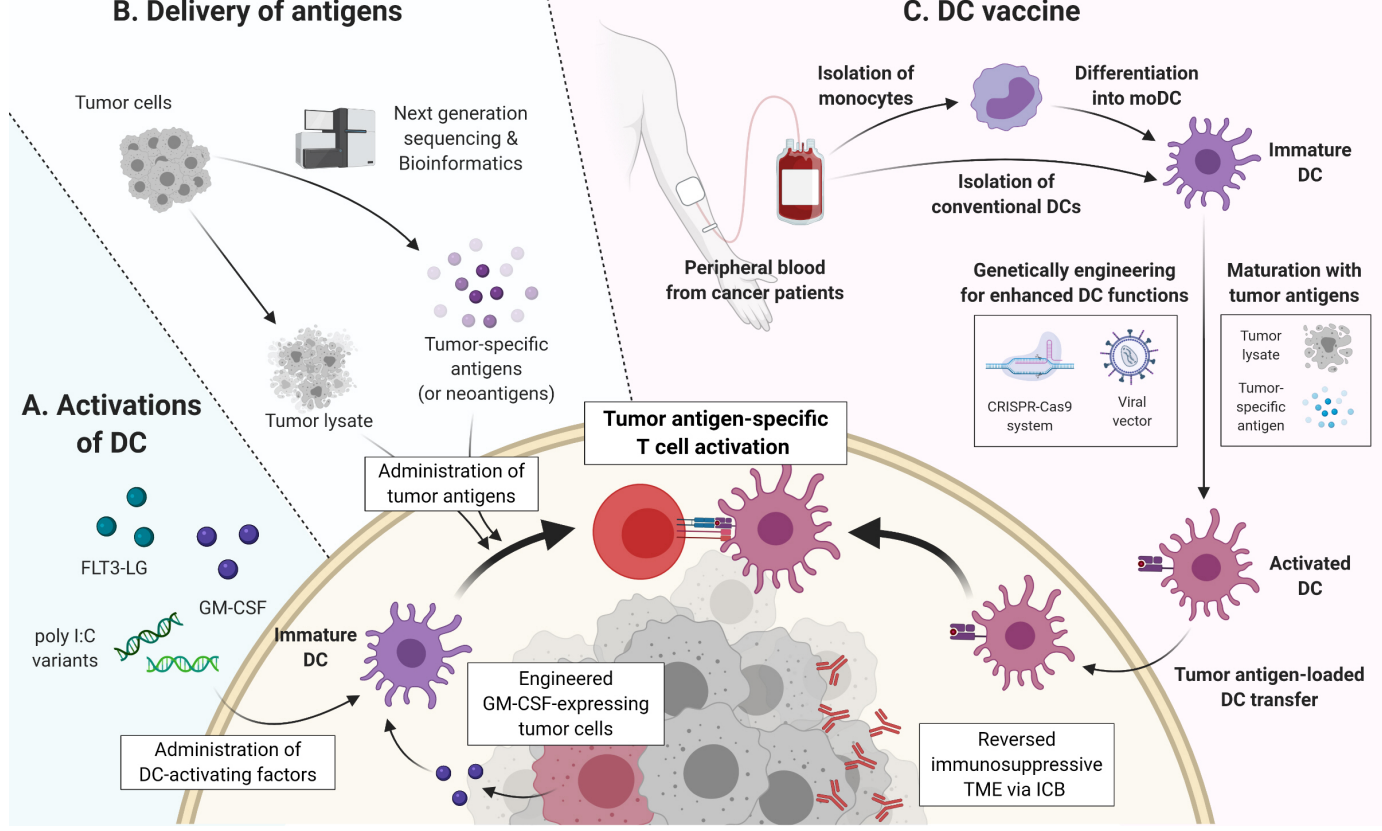

Fig. 3. The scheme of DC-based cancer immunotherapies. (A) Direct activation of DCs by the administration of several molecules, such as FLT3-LG, GM-CSF, and poly I:C variants, is one strategy of DC-based immunotherapies. In addition, it is the other strategy to genetically engineer tumor cells to produce GM-CSF. (B) Together with DC activation, the administration of tumor-derived antigens induces DCs to promote tumor-specific immune responses. Tumor-derived antigens can be delivered as whole-tumor lysates or specific antigens including neoantigens, which are predicted by next generation sequencing and bioinformatic tools. (C) For DC vaccine, immature DCs, which are conventional DCs or moDCs, are isolated from the peripheral blood of cancer patients, and these cells are maturated and activated with tumor antigens as tumor lysates or specific antigens. In order to improve the functionality, DCs are engineered by using genetical tools, such as the CRISPR-Cas9 system and viral vectors. Then, activated DCs loaded with tumor antigens are reinfused into patients, leading to the induction of an antigen-specific immune response. Since immunosuppressive TME might deteriorate the efficacy of a DC vaccine, ICB therapies are combined with DC vaccine in order to reverse TME.

vaccine platform engineered to produce GM-CSF (72). Although results in clinical trials for prostate cancer were unsatisfactory, other clinical trials combining GVAX with other therapies are still in progress (73). Another platform, talimogene laherparaepvec (T-VEC), which uses an attenuated herpes simplex virus to express GM-CSF, has been approved by the United States Food and Drug Administration (US FDA) for treating advanced stage III and IV melanoma (74). Administration of T-VEC is associated with elevated levels of $\mathrm{CD}^{+} \mathrm{T}$ cells and a reduction in immunosuppressive cells, such as regulatory $T$ cells and myeloid-derived suppressor cells, in the tumor microenvironment (75).

In addition to cytokines, TLR signaling is a strong stimulator of DC activation (Fig. 3A). The cDC1 subset, an important player in antitumor immunity, mainly expresses TLR3. Thus, the TLR3 agonist poly I:C has been developed as a cancer treatment to activate $\mathrm{cDC} 1 \mathrm{~s}$. Despite the effect of poly I:C on DC activation, it is difficult to use this molecule clinically because of the high risk of toxic reactions found in clinical trials (76). Since these trials, there have been many efforts to develop substitutes with less toxicity, such as poly I:C variants (e.g., poly-ICLC and poly I: $\mathrm{C}_{12} \mathrm{U}$ ) and nanoparticle-encapsulated poly I:C. In a pilot study, poly-ICLC was well tolerated by solid-cancer patients and induced an increase in $\mathrm{T}$ cells in intratumoral tissues of patients with a progressive disease. In addition, this treatment upregulated the expression of genes associated with chemokine activity, as well as T-cell activation and antigen presentation in the tumor and PBMCs of individual patients (77). Another variant, poly I: $\mathrm{C}_{12} \mathrm{U}$, has also been evaluated with human monocyte-derived DCs in vitro. This treatment increases the expression of $\mathrm{MHCll}$ and co-stimulatory molecules, and induces more IL-12 and less IL-10 than poly I:C treatment does (78). Finally, in preclinical trials with melanoma patients, a nanoplexed poly I:C showed dramatic tumor rejection with improved cytotoxic T-cell functions and synergistic effects with anti-PD-1 and anti-CD137 immunotherapy (79).

The cGAS-STING pathway is critical for DC activation in the antitumor immune response (Fig. 3A). While DNA sensing in DCs is regulated by SIRP $\alpha$ signaling, CD47 blockade enhanced cGAS-STING signaling by increasing the sensing of tumor-derived mitochondrial DNA in SIRP $\alpha^{+}$CDC2 subsets, resulting in type I IFN production and antitumor immune responses (30). 
Additionally, the administration of the STING agonist induces tumor rejection and improved antitumor immunity in a murine melanoma model (80).

\section{DELIVERY OF ANTIGENS}

As mentioned above, DCs are primarily involved in antigen presentation, especially in $\mathrm{CD}^{+}{ }^{+} \mathrm{T}$-cell priming in antitumor immunity. Thus, delivering tumor-derived antigens to DCs has been a key strategy used in developing cancer treatments (Fig. 3B) (81). Two main types of antigens have been used for delivery, namely, whole-tumor lysates and specific-tumor antigens (4). Whole-tumor lysates are relatively simple to use, since selecting specific-tumor-derived antigens is not required. Moreover, autologous tumor cells have more potential for success than do allogenic tumor-cell lines, because they already contain all of the mutant antigens present in an individual patient (82). Recently, a prototype for a generic melanoma vaccine (TRIMELVax) was generated from a mixture of three human melanoma-cell lines by a heat-shock process. Upon administration into a murine melanoma model, the antigens of TRIMELVax were phagocytosed by the $\mathrm{CDC} 1$ subset, which induced $\mathrm{CD}^{+}{ }^{+}$-cell priming and activation, and ultimately tumor rejection (83). In addition, whole-tumor lysates can be delivered within liposomal spherical nucleic acids (SNAs) composed of adjuvants. For example, a complex consisting of murine triple-negative breastcancer cell lysates encapsulated with SNAs consisting of CpG on the surface induced tumor rejection and in vitro activation of BM-DCs (84).

However, whole-tumor lysates also contain immunosuppressive molecules, such as vascular endothelial growth factor, soluble FAS ligand, IL-10, and TGF- $\beta 1$ (82). Thus, the selection of specific antigens from tumor cells is another method used for cancer treatment. Among tumor-associated antigens, neoantigens are effective therapeutic targets, since they may exhibit lower immune tolerance and induce natural antitumor T-cell responses (85). Indeed, tumors with high somatic mutation rates are associated with the objective response rates to PD-1 and PD-L1 blockade, whereas tumors with few mutations produced lower response rates $(85,86)$. In addition, the quality of neoantigens, which is defined as the potential to promote T-cell activation, can be a prognostic indicator of survival in pancreatic-cancer patients (87). The feasibility, safety, and immunogenicity of this method was demonstrated in studies of melanoma and glioblastoma patients who were vaccinated with neoantigens extracted from cancer patients and were selected based on predictions of high-affinity binding of autologous human leukocyte antigen using machine-learning approaches $(88,89)$.

The maturity of DCs is an important consideration for the success of delivering tumor antigens for cancer treatment. Therefore, the antigens are administered together with adjuvants, such as GM-CSF and DC-targeting antibodies, against DEC-205 $(4,5)$. In some clinical trials, GM-CSF was administered with autologous tumor-cell lysates or lysate-pulsed DCs in mesothelioma and metastatic RCC patients, respectively (90, 91). NY-ESO-1, a cancer/testis antigen expressed in the testicular germ cells of normal adults, was engineered to be fused with an antibody targeting DEC-205 to induce cross-presentation of DCs and activation of NY-ESO-1-specific T cells from PBMCs of cancer patients (92). In addition, DEG-205 antibody fused with a partial peptide of MAGE, a known melanoma antigen, induces DC maturation and pro-inflammatory cytokine production by MAGE-specific CD4 ${ }^{+}$T cells (93).

\section{VACCINES}

DC vaccines are developed using natural endogenous DCs or ex vivo monocyte-derived DCs isolated from autologous PBMCs of cancer patients who have been pulsed with tumor lysates or tumor-associated antigens (Fig. 3C). This therapeutic strategy delivers antigen-loaded DCs stimulated with pro-inflammatory cytokines to promote the antitumor immune response of tumor antigen-specific $\mathrm{CD}^{+} \mathrm{T}$ cells. In clinical trials, the toxicity of DC vaccines was much lower than that of other cancer therapies, including chemotherapy, radiotherapy, and ICB (94, 95). Sipuleucel-T (Provenge), which was developed with a fusion protein consisting of the tumor antigen prostatic acid phosphate and GM-CSF, is the first DC-based vaccine approved for the treatment of prostate cancer (96). However, despite the reduced toxicity, DC vaccines, including Sipueleucel-T, have exhibited limited clinical benefit $(97,98)$. Many factors may be responsible for the reduced efficacy of DC vaccines, including immunosuppressive tumor microenvironments and immune evasion of tumor cells, both of which can disable the function of DCs. Therefore, various attempts to improve the efficacy of DC vaccines are under way, including neoantigentargeted approaches, genetic engineering approaches, and combined treatment with ICB.

With the development of next generation sequencing and bioinformatics tools, it is possible to identify patient-specific tumor antigens, including neoantigens, with a high potential for immunogenicity (97). Although this approach has major challenges, such as long lead times and high costs, the application of neoantigens to DC vaccines may improve their therapeutic efficacy. A recent phase I clinical trial demonstrated the potential of personalized DC vaccines based on neoantigens to induce a diverse neoantigen-specific T-cell repertoire (99).

In order to increase DC functionality, several genetic approaches have been applied, including RNA interference, clustered regulatory interspaced short palindromic repeats (CRISPR)/ CRISP-associated protein 9 (Cas9), and viral transduction (100). To increase antigen presentation by DCs, extracellular vesicleinternalizing receptor, which can selectively uptake tumor-cellderived extracellular vesicles, can be transduced into DCs via viral vectors. In addition, overexpression of CCR7 on DCs via gene transduction has been shown to augment DC migration into tumor dLNs $(101,102)$. Likewise, microRNA-155 overex- 
pression promotes CCR7 expression and IL-12 production by DCs, leading to elevated migration and activation of DCs (103, 104). DCs transduced with $\mathrm{cd} 40 \mathrm{O}$, cd70, and t/r4 genes also improved the functionality of DC vaccines (105). Furthermore, the administration of DCs modified by adenoviral-vector-expressed CCL21 induced T-cell infiltration into the tumor microenvironment of a murine tumor model and clinical trial (106, 107).

Since ICB therapy can reverse the immunosuppressive microenvironment, combining it with DC vaccines may be an effective cancer treatment. Several recent studies have demonstrated the potential of this combination therapy in various tumor models. Mouse splenic cDC1s loaded with tumor lysate can activate $\mathrm{CD}^{+} \mathrm{T}$ cells optimally in vivo and synergize antitumor immunity with PD-1 blockade (108). In addition, PD-1 blockade increased the efficacy of DC vaccines when combined with tumor antigens and CCL21 in a mouse lung-cancer model (109). Furthermore, a combined treatment of DC vaccine and PD-L1 blockade improved overall survival and tumor rejection in a murine hepatocellular carcinoma model (110).

\section{PERSPECTIVE}

Since cancer has a high death rate, there is enormous focus on developing effective therapies to treat the disease, and understanding the immune response in the tumor microenvironment is important for this development. DCs are a major immune cell type involved in presenting tumor antigens and inducing adaptive immune responses. Among DC subsets, cDC1s are critical for inducing the antitumor immunity of $\mathrm{CD}^{+} \mathrm{T}$ cells via cross-presentation, as well as early priming of $\mathrm{CD} 4^{+} \mathrm{T}$ cells. cDC2s also participate in antitumor responses by primarily activating $\mathrm{CD}^{+}{ }^{+} \mathrm{T}$ cells. However, $\mathrm{cDC}$ subsets are intrinsically programmed to be immunotolerogenic upon tumor antigen uptake. Whereas pDCs produce considerable type I IFN to promote antitumor immunity, most of them become tolerogenic by tumor-cell regulation. The functionality of moDCs also depends on factors within the tumor microenvironment. Furthermore, DCs are involved in the underlying mechanisms of several commonly used cancer therapies, such as radiation therapy, chemotherapy, and ICB. Therefore, increasing DC functionality can be an effective strategy for improving current therapies.

Although the clinical benefit of DC vaccines is currently limited due to restricted types of tumor antigens and the immunosuppressive functions of tumors, various trials using different technological advances are ongoing to improve their therapeutic efficacy. Specifically, promising antigens are being discovered with the radical development of bioinformatics tools and next generation sequencing. In addition, ICB can directly reverse the suppressed functions of DCs, as well as other immune cells interacting with DCs, such as T cells and NK cells. To this end, DCs have been leveraged as a means to deliver tumor-derived antigens to $\mathrm{T}$ cells and induce tumor- specific immune responses. Therefore, based on the comprehensive mechanisms of DCs in the tumor microenvironment, targeting the activity of DCs is critical for advancing current cancer therapies.

\section{ACKNOWLEDGEMENTS}

This work was supported by the National Research Foundation (NRF-2018M3A9H3024611), Republic of Korea and National Research Council of Science and Technology (NST) funded by the Ministry of Science and ICT (Grant No. CRC-16-01-KRICT), Republic of Korea. Figures were created with BioRender.com.

\section{CONFLICTS OF INTEREST}

The authors have no conflicting interests.

\section{REFERENCES}

1. Mittal D, Gubin MM, Schreiber RD and Smyth MJ (2014) New insights into cancer immunoediting and its three component phases--elimination, equilibrium and escape. Curr Opin Immunol 27, 16-25

2. Chen Daniel S and Mellman I (2013) Oncology meets immunology: the cancer-immunity cycle. Immunity 39 , $1-10$

3. Gaudino SJ and Kumar P (2019) Cross-talk between antigen presenting cells and T cells impacts intestinal homeostasis, bacterial infections, and tumorigenesis. Front Immunol 10, 360

4. Wculek SK, Cueto FJ, Mujal AM, Melero I, Krummel MF and Sancho D (2020) Dendritic cells in cancer immunology and immunotherapy. Nat Rev Immunol 20, 7-24

5. Gardner A, de Mingo Pulido Á and Ruffell B (2020) Dendritic cells and their role in immunotherapy. Front Immunol 11, 924-924

6. Hildner K, Edelson BT, Purtha WE et al (2008) Batf3 deficiency reveals a critical role for CD8 $\alpha$ dendritic cells in cytotoxic T cell immunity. Science 322, 1097-1100

7. Sánchez-Paulete AR, Cueto FJ, Martínez-López $M$ et al (2016) Cancer immunotherapy with immunomodulatory anti-CD137 and anti-PD-1 monoclonal antibodies requires BATF3-dependent dendritic cells. Cancer Discov 6, 71-79

8. Spranger S, Dai D, Horton B and Gajewski TF (2017) Tumor-residing Batf3 dendritic cells are required for effector T cell trafficking and adoptive $\mathrm{T}$ cell therapy. Cancer Cell 31, 711-723.e714

9. Jongbloed SL, Kassianos AJ, McDonald KJ et al (2010) Human CD141 + (BDCA-3) + dendritic cells (DCs) represent a unique myeloid DC subset that cross-presents necrotic cell antigens. J Exp Med 207, 1247-1260

10. Broz Miranda L, Binnewies M, Boldajipour B et al (2014) Dissecting the tumor myeloid compartment reveals rare activating antigen-presenting cells critical for T cell immunity. Cancer Cell 26, 638-652

11. Roberts EW, Broz ML, Binnewies M et al (2016) Critical role for CD103+/CD141 + dendritic cells bearing CCR7 for tumor antigen trafficking and priming of $\mathrm{T}$ cell immu- 
nity in melanoma. Cancer Cell 30, 324-336

12. Binnewies M, Mujal AM, Pollack JL et al (2019) Unleashing type-2 dendritic cells to drive protective antitumor CD4 + T cell immunity. Cell 177, 556-571.e516

13. Ferris ST, Durai $\mathrm{V}, \mathrm{Wu} R$ et al (2020) CDC1 prime and are licensed by $\mathrm{CD} 4+\mathrm{T}$ cells to induce anti-tumour immunity. Nature 584, 624-629

14. Salmon H, Idoyaga J, Rahman A et al (2016) Expansion and activation of CD103 + dendritic cell progenitors at the tumor site enhances tumor responses to therapeutic PD-L1 and BRAF inhibition. Immunity 44, 924-938

15. Novak L, Igoucheva O, Cho S and Alexeev V (2007) Characterization of the CCL21-mediated melanoma-specific immune responses and in situ melanoma eradication. Mol Cancer Ther 6, 1755

16. Shields JD, Kourtis IC, Tomei AA, Roberts JM and Swartz MA (2010) Induction of lymphoidlike stroma and immune escape by tumors that express the chemokine CCL21. Science 328, 749

17. Böttcher JP and Reis e Sousa C (2018) The role of type 1 conventional dendritic cells in cancer immunity. Trends Cancer 4, 784-792

18. Dannull J, Nair S, Su Z et al (2005) Enhancing the immunostimulatory function of dendritic cells by transfection with mRNA encoding OX40 ligand. Blood 105, 3206-3213

19. Buchan SL, Fallatah M, Thirdborough SM et al (2018) PD-1 blockade and CD27 stimulation activate distinct transcriptional programs that synergize for $\mathrm{CD}^{+} \mathrm{T}$-celldriven antitumor immunity. Clin Cancer Res 24, 23832394

20. Martínez-López M, Iborra S, Conde-Garrosa R and Sancho D (2015) Batf3-dependent CD103 + dendritic cells are major producers of IL-12 that drive local Th1 immunity against Leishmania major infection in mice. Eur J Immunol 45, 119-129

21. Ruffell B, Chang-Strachan D, Chan V et al (2014) Macrophage IL-10 blocks CD8 + T cell-dependent responses to chemotherapy by suppressing IL-12 expression in intratumoral dendritic cells. Cancer Cell 26, 623-637

22. Chow MT, Ozga AJ, Servis RL et al (2019) Intratumoral activity of the CXCR3 chemokine system is required for the efficacy of anti-PD-1 therapy. Immunity 50, 1498-1512. e1495

23. Enamorado M, Iborra S, Priego E et al (2017) Enhanced anti-tumour immunity requires the interplay between resident and circulating memory CD8 + T cells. Nature 8, 16073

24. Mittal D, Vijayan D, Putz EM et al (2017) Interleukin-12 from $\mathrm{CD}_{103}{ }^{+}$Batf3-dependent dendritic cells required for NK-cell suppression of metastasis. Cancer Immnol 5, 1098

25. Böttcher JP, Bonavita E, Chakravarty P et al (2018) NK cells stimulate recruitment of $\mathrm{CDC} 1$ into the tumor microenvironment promoting cancer immune control. Cell 172, 1022-1037.e1014

26. Barry KC, Hsu J, Broz ML et al (2018) A natural killer-dendritic cell axis defines checkpoint therapy-responsive tumor microenvironments. Nat Med 24, 11781191
27. Maier B, Leader AM, Chen ST et al (2020) A conserved dendritic-cell regulatory program limits antitumour immunity. Nature 580, 257-262

28. Zong J, Keskinov AA, Shurin GV and Shurin MR (2016) Tumor-derived factors modulating dendritic cell function. Cancer Immnol Immunother 65, 821-833

29. Gottfried E, Kunz-Schughart LA, Ebner S et al (2006) Tumor-derived lactic acid modulates dendritic cell activation and antigen expression. Blood 107, 2013-2021

30. Xu MM, Pu Y, Han D et al (2017) Dendritic cells but not macrophages sense tumor mitochondrial DNA for crosspriming through signal regulatory protein $\alpha$ signaling. Immunity 47, 363-373.e365

31. Villablanca EJ, Raccosta L, Zhou D et al (2010) Tumormediated liver $X$ receptor- $\alpha$ activation inhibits $C C$ chemokine receptor-7 expression on dendritic cells and dampens antitumor responses. Nat Med 16, 98-105

32. Villadangos JA and Young L (2008) Antigen-presentation properties of plasmacytoid dendritic cells. Immunity 29, 352-361

33. Zitvogel L, Galluzzi L, Kepp O, Smyth MJ and Kroemer G (2015) Type I interferons in anticancer immunity. Nat Rev Immunol 15, 405-414

34. Fuertes MB, Kacha AK, Kline J et al (2011) Host type I IFN signals are required for antitumor CD8 $+\mathrm{T}$ cell responses through CD8 + dendritic cells. J Exp Med 208, 2005-2016

35. Diamond MS, Kinder M, Matsushita $\mathrm{H}$ et al (2011) Type I interferon is selectively required by dendritic cells for immune rejection of tumors. J Exp Med 208, 1989-2003

36. Zilionis R, Engblom C, Pfirschke C et al (2019) Singlecell transcriptomics of human and mouse lung cancers reveals conserved myeloid populations across individuals and species. Immunity 50, 1317-1334.e1310

37. Aspord C, Leccia M-T, Charles J and Plumas J (2013) Plasmacytoid dendritic cells support melanoma progression by promoting Th2 and regulatory immunity through OX40L and ICOSL. Cancer Immunol Res 1, 402

38. Conrad C, Gregorio J, Wang Y-H et al (2012) Plasmacytoid dendritic cells promote immunosuppression in ovarian cancer via icos costimulation of Foxp3 + T-regulatory cells. Cancer Res 72, 5240

39. Faget J, Bendriss-Vermare N, Gobert M et al (2012) ICOS-ligand expression on plasmacytoid dendritic cells supports breast cancer progression by promoting the accumulation of immunosuppressive CD4 + T cells. Cancer Res 72,6130

40. Labidi-Galy SI, Treilleux I, Goddard-Leon S et al (2012) Plasmacytoid dendritic cells infiltrating ovarian cancer are associated with poor prognosis. Oncolmmunology 1, 380-382

41. Pedroza-Gonzalez A, Zhou G, Vargas-Mendez E et al (2015) Tumor-infiltrating plasmacytoid dendritic cells promote immunosuppression by Tr1 cells in human liver tumors. Oncoimmunology 4, e1008355-e1008355

42. Treilleux I, Blay J-Y, Bendriss-Vermare $\mathrm{N}$ et al (2004) Dendritic cell infiltration and prognosis of early stage breast cancer. Clin Cancer Res 10, 7466

43. Wei S, Kryczek I, Zou L et al (2005) Plasmacytoid dendritic cells induce CD8 + regulatory T cells in human 
ovarian carcinoma. Cancer Res 65, 5020

44. Sisirak V, Vey N, Goutagny N et al (2013) Breast cancer-derived transforming growth factor- $\beta$ and tumor necrosis factor- $\alpha$ compromise interferon- $\alpha$ production by tumor-associated plasmacytoid dendritic cells. Int J Cancer 133, 771-778

45. Terra M, Oberkampf M, Fayolle C et al (2018) Tumorderived TGF $\beta$ alters the ability of plasmacytoid dendritic cells to respond to innate immune signaling. Cancer Res 78, 3014

46. Bruchhage K-L, Heinrichs S, Wollenberg B and Pries R (2018) IL-10 in the microenvironment of HNSCC inhibits the CpG ODN induced IFN- $\alpha$ secretion of pDCs. Oncol Lett 15, 3985-3990

47. Bi E, Li R, Bover LC et al (2018) E-cadherin expression on multiple myeloma cells activates tumor-promoting properties in plasmacytoid DCs. J Clin Investig 128, 4821-4831

48. Nakano H, Lin KL, Yanagita $M$ et al (2009) Blood-derived inflammatory dendritic cells in lymph nodes stimulate acute $\mathrm{T}$ helper type 1 immune responses. Nat Immunol 10, 394-402

49. Sharma MD, Rodriguez PC, Koehn BH et al (2018) Activation of p53 in immature myeloid precursor cells controls differentiation into Ly6c + CD103 + monocytic antigen-presenting cells in tumors. Immunity 48, 91-106.e106

50. Diao J, Gu H, Tang M, Zhao J and Cattral MS (2018) Tumor dendritic cells (DCs) derived from precursors of conventional DCs are dispensable for intratumor CTL responses. J Immunol 201, 1306

51. Qian B-Z, Li J, Zhang $\mathrm{H}$ et al (2011) CCL2 recruits inflammatory monocytes to facilitate breast-tumour metastasis. Nature 475, 222-225

52. Spary LK, Salimu J, Webber JP, Clayton A, Mason MD and Tabi Z (2014) Tumor stroma-derived factors skew monocyte to dendritic cell differentiation toward a suppressive CD14+ PD-L1 + phenotype in prostate cancer. Oncoimmunology 3, e955331

53. Laoui D, Keirsse J, Morias Y et al (2016) The tumour microenvironment harbours ontogenically distinct dendritic cell populations with opposing effects on tumour immunity. Nat Commun 7, 13720

54. Bakdash G, Buschow SI, Gorris MAJ et al (2016) Expansion of a BDCA1 + CD14 + myeloid cell population in melanoma patients may attenuate the efficacy of dendritic cell vaccines. Cancer Res 76, 4332

55. Deng L, Liang H, Xu M et al (2014) STING-dependent cytosolic dna sensing promotes radiation-induced type I interferon-dependent antitumor immunity in immunogenic tumors. Immunity 41, 843-852

56. Ghiringhelli F, Apetoh L, Tesniere A et al (2009) Activation of the NLRP3 inflammasome in dendritic cells induces IL-1 $\beta$-dependent adaptive immunity against tumors. Nat Med 15, 1170-1178

57. Apetoh L, Ghiringhelli F, Tesniere A et al (2007) Tolllike receptor 4-dependent contribution of the immune system to anticancer chemotherapy and radiotherapy. Nat Med 13, 1050-1059

58. Vacchelli E, Ma Y, Baracco EE et al (2015) Chemotherapy-induced antitumor immunity requires formyl peptide receptor 1 . Science 350, 972-978

59. Lecciso M, Ocadlikova D, Sangaletti S et al (2017) ATP release from chemotherapy-treated dying leukemia cells elicits an immune suppressive effect by increasing regulatory $\mathrm{T}$ cells and tolerogenic dendritic cells. Front Immunol 8, 1918

60. Vanpouille-Box C, Alard A, Aryankalayil MJ et al (2017) DNA exonuclease Trex1 regulates radiotherapy-induced tumour immunogenicity. Nat Commun 8, 15618

61. Hou Y, Liang H, Rao E et al (2018) Non-canonical NF$\kappa B$ antagonizes STING sensor-mediated DNA sensing in radiotherapy. Immunity 49, 490-503.e494

62. Marigo I, Zilio S, Desantis G et al (2016) T cell cancer therapy requires CD40-CD40L activation of tumor necrosis factor and inducible nitric-oxide-synthase-producing dendritic cells. Cancer Cell 30, 377-390

63. Oba T, Hoki T, Yamauchi T et al (2020) A critical role of CD40 and CD70 signaling in conventional type 1 dendritic cells in expansion and antitumor efficacy of adoptively transferred tumor-specific T cells. J Immunol 205, 1867-1877

64. Kalbasi A and Ribas A (2020) Tumour-intrinsic resistance to immune checkpoint blockade. Nat Rev Immunol 20, 25-39

65. Mayoux M, Roller A, Pulko V et al (2020) Dendritic cells dictate responses to PD-L1 blockade cancer immunotherapy. Sci Transl Med 12, eaav7431

66. Schetters STT, Rodriguez E, Kruijssen LJW et al (2020) Monocyte-derived APCs are central to the response of PD1 checkpoint blockade and provide a therapeutic target for combination therapy. J Immunother Cancer 8, $\mathrm{e} 000588$

67. Morrison AH, Diamond MS, Hay CA, Byrne KT and Vonderheide RH (2020) Sufficiency of CD40 activation and immune checkpoint blockade for T cell priming and tumor immunity. Proc Natl Acad Sci U S A 117, 8022

68. Garris CS, Arlauckas SP, Kohler RH et al (2018) Successful anti-PD-1 cancer immunotherapy requires T cell- dendritic cell crosstalk involving the cytokines IFN- $\gamma$ and IL-12. Immunity 49, 1148-1161.e1147

69. Cauwels A, Van Lint S, Paul F et al (2018) Delivering type I interferon to dendritic cells empowers tumor eradication and immune combination treatments. Cancer Res 78, 463

70. Wang H, Hu S, Chen $X$ et al (2017) cGAS is essential for the antitumor effect of immune checkpoint blockade. Proc Natl Acad Sci U S A 114, 1637

71. Alloatti A, Rookhuizen DC, Joannas L et al (2017) Critical role for Sec22b-dependent antigen cross-presentation in antitumor immunity. J Exp Med 214, 2231-2241

72. Nemunaitis J (2005) Vaccines in cancer: GVAX ${ }^{\mathbb{R}}$, a GM-CSF gene vaccine. Expert Rev Vaccines 4, 259-274

73. Yan W-L, Shen K-Y, Tien C-Y, Chen Y-A and Liu S-J (2017) Recent progress in GM-CSF-based cancer immunotherapy. Immunotherapy 9, 347-360

74. Bommareddy PK, Patel A, Hossain S and Kaufman HL (2017) Talimogene laherparepvec (T-VEC) and other oncolytic viruses for the treatment of melanoma. Am J Clin Dermatol 18, 1-15

75. Kaufman HL, Kim DW, DeRaffele G, Mitcham J, Coffin 
RS and Kim-Schulze S (2010) Local and distant immunity induced by intralesional vaccination with an oncolytic herpes virus encoding gm-csf in patients with stage IIIc and IV melanoma. Ann Surg Oncol 17, 718-730

76. Robinson RA, DeVita VT, Levy HB, Baron S, Hubbard SP and Levine AS (1976) A phase I-II trial of multipledose polyriboinosinic-polyribocytidylic acid in patients with leukemia or solid tumors. J Natl Cancer Inst 57, 599-602

77. Kyi C, Roudko V, Sabado R et al (2018) Therapeutic immune modulation against solid cancers with intratumoral poly-ICLC: a pilot trial. Clin Cancer Res 24, 49374948

78. Navabi H, Jasani B, Reece A et al (2009) A clinical grade poly I:C-analogue (Ampligen ${ }^{\mathrm{R}}$ ) promotes optimal DC maturation and Th1-type $\mathrm{T}$ cell responses of healthy donors and cancer patients in vitro. Vaccine 27, 107-115

79. Aznar MA, Planelles L, Perez-Olivares M et al (2019) Immunotherapeutic effects of intratumoral nanoplexed poly I:C. J Immunother Cancer 7, 116

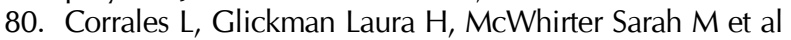
(2015) Direct activation of sting in the tumor microenvironment leads to potent and systemic tumor regression and immunity. Cell Rep 11, 1018-1030

81. Finn OJ (2017) Human tumor antigens yesterday, today, and tomorrow. Cancer Immunol Res 5, 347

82. Harari A, Graciotti M, Bassani-Sternberg M and Kandalaft LE (2020) Antitumour dendritic cell vaccination in a priming and boosting approach. Nat Rev Drug Discov $19,635-652$

83. Gleisner MA, Pereda C, Tittarelli A et al (2020) A heatshocked melanoma cell lysate vaccine enhances tumor infiltration by prototypic effector T cells inhibiting tumor growth. J Immunother Cancer 8, e000999

84. Callmann CE, Cole LE, Kusmierz CD, Huang Z, Horiuchi D and Mirkin CA (2020) Tumor cell lysate-loaded immunostimulatory spherical nucleic acids as therapeutics for triple-negative breast cancer. Proc Natl Acad Sci U S A 117, 17543

85. Yarchoan $M$, Johnson BA, Lutz ER, Laheru DA and Jaffee EM (2017) Targeting neoantigens to augment antitumour immunity. Nat Rev Cancer 17, 209-222

86. Rizvi NA, Hellmann MD, Snyder A et al (2015) Cancer immunology. Mutational landscape determines sensitivity to PD-1 blockade in non-small cell lung cancer. Science 348, 124-128

87. Balachandran VP, Łuksza M, Zhao JN et al (2017) Identification of unique neoantigen qualities in long-term survivors of pancreatic cancer. Nature 551, 512-516

88. Ott PA, Hu Z, Keskin DB et al (2017) An immunogenic personal neoantigen vaccine for patients with melanoma. Nature 547, 217-221

89. Keskin DB, Anandappa AJ, Sun J et al (2019) Neoantigen vaccine generates intratumoral $\mathrm{T}$ cell responses in phase lb glioblastoma trial. Nature 565, 234-239

90. Kim JH, Lee Y, Bae Y-S et al (2007) Phase I/II study of immunotherapy using autologous tumor lysate-pulsed dendritic cells in patients with metastatic renal cell carcinoma. Clin Immunol 125, 257-267

91. Powell A, Creaney J, Broomfield S, Van Bruggen I and
Robinson B (2006) Recombinant GM-CSF plus autologous tumor cells as a vaccine for patients with mesothelioma. Lung Cancer 52, 189-197

92. Tsuji T, Matsuzaki J, Kelly MP et al (2011) Antibodytargeted NY-ESO-1 to mannose receptor or DEC-205 in vitro elicits dual human CD8 + and CD4 + T cell responses with broad antigen specificity. J Immunol 186, 1218

93. Birkholz K, Schwenkert M, Kellner C et al (2010) Targeting of DEC-205 on human dendritic cells results in efficient MHC class II-restricted antigen presentation. Blood $116,2277-2285$

94. Anguille $S$, Smits EL, Lion E, van Tendeloo VF and Berneman ZN (2014) Clinical use of dendritic cells for cancer therapy. Lancet Oncol 15, e257-e267

95. Draube A, Klein-González N, Mattheus S et al (2011) Dendritic cell based tumor vaccination in prostate and renal cell cancer: a systematic review and meta-analysis. PLoS One 6, e18801

96. Kantoff PW, Higano CS, Shore ND et al (2010) Sipuleucel-T immunotherapy for castration-resistant prostate cancer. N Engl J Med 363, 411-422

97. Mastelic-Gavillet B, Balint K, Boudousquie C, Gannon PO and Kandalaft LE (2019) Personalized dendritic cell vaccines - recent breakthroughs and encouraging clinical results. Front Immunol 10, 766

98. van Willigen WW, Bloemendal $M$, Gerritsen WR, Schreibelt G, de Vries IJM and Bol KF (2018) Dendritic cell cancer therapy: vaccinating the right patient at the right time. Front Immunol 9, 2265

99. Carreno BM, Magrini V, Becker-Hapak M et al (2015) A dendritic cell vaccine increases the breadth and diversity of melanoma neoantigen-specific T cells. Science 348, 803

100. Perez CR and De Palma M (2019) Engineering dendritic cell vaccines to improve cancer immunotherapy. Nat Commun 10, 5408

101. Okada N, Mori N, Koretomo R et al (2005) Augmentation of the migratory ability of DC-based vaccine into regional lymph nodes by efficient CCR7 gene transduction. Gene Ther 12, 129-139

102. Yang X, Lian K, Meng T et al (2018) Immune adjuvant targeting micelles allow efficient dendritic cell migration to lymph nodes for enhanced cellular immunity. ACS Appl Mater Interfaces 10, 33532-33544

103. Wang J, Iwanowycz S, Yu F et al (2016) microRNA-155 deficiency impairs dendritic cell function in breast cancer. Oncoimmunology 5, e1232223

104. Lind EF, Millar DG, Dissanayake D et al (2015) miR-155 upregulation in dendritic cells is sufficient to break tolerance in vivo by negatively regulating SHIP1. J Immunol 195, 4632

105. Wilgenhof S, Corthals J, Heirman C et al (2016) Phase II study of autologous monocyte-derived mrna electroporated dendritic cells (TriMixDC-MEL) plus ipilimumab in patients with pretreated advanced melanoma. J Clin Oncol 34, 1330-1338

106. Yang S-C, Hillinger S, Riedl $\mathrm{K}$ et al (2004) Intratumoral administration of dendritic cells overexpressing CCL21 generates systemic antitumor responses and confers tumor immunity. Clin Cancer Res 10, 2891 
107. Lee JM, Lee M-H, Garon E et al (2017) Phase I trial of intratumoral injection of CCL21 gene-modified dendritic cells in lung cancer elicits tumor- specific immune responses and CD8 + T-cell infiltration. Clin Cancer Res 23, 45564568

108. Wculek SK, Amores-Iniesta J, Conde-Garrosa R, Khouili SC, Melero I and Sancho D (2019) Effective cancer immunotherapy by natural mouse conventional type-1 dendritic cells bearing dead tumor antigen. J Immunother
Cancer 7, 100

109. Kadam P and Sharma S (2020) PD-1 immune checkpoint blockade promotes therapeutic cancer vaccine to eradicate lung cancer. Vaccines 8, 317

110. Teng C-F, Wang T, Wu T-H et al (2020) Combination therapy with dendritic cell vaccine and programmed death ligand 1 immune checkpoint inhibitor for hepatocellular carcinoma in an orthotopic mouse model. Ther Adv Med Oncol 12, 1758835920922034 